\title{
Microstructure and Properties of Ni-SiC Nanocomposites Fabricated by Ultrasonic-Assisted Electrodeposition
}

\author{
Chunyang $\mathrm{Ma}^{1}$, Danqiong $\mathrm{Zhao}^{1}$, Hanzhao Xia ${ }^{2}$, Fafeng Xia ${ }^{1}$, Zhipeng $\mathrm{Ma}^{1,{ }^{*}}$, Tom Williams ${ }^{3}$ \\ ${ }^{1}$ College of Mechanical Science and Engineering, Northeast Petroleum University, Daqing 163318, \\ China; \\ ${ }^{2}$ Shandong Tai'an No. 1 Senior High School, Tai'an 271000, China \\ ${ }^{3}$ Department of Mechanical \& Materials Engineering, University of Cincinnati, Cincinnati, OH 45221, \\ USA \\ *E-mail: chunyangandma1@ 163.com
}

doi: $10.20964 / 2020.05 .56$

Received: 9 January 2020 / Accepted: 17 February 2020 / Published: 10 April 2020

\begin{abstract}
In this research, $\mathrm{Ni}-\mathrm{SiC}$ nanocomposites (NCs) were effectively prepared by using ultrasonic-assisted electrodeposition (UAED). Effect of ultrasonic power on surface morphology, microstructure, phase composition and other NC properties was studied by scanning electron and atomic force microscopies, $\mathrm{X}$-ray diffractometry as well as by microhardness, abrasion and electrochemical tests. The results indicated that Ni-SiC-300 NC, deposited at $300 \mathrm{~W}$, showed smooth and fine-grained surface morphology with SiC nanoparticles (NPs) evenly distributed on the NC surface. As ultrasonic power was gradually changed from 100 to $400 \mathrm{~W}$, XRD peaks corresponding to Ni matrix first broadened but then narrowed. Thus, only certain ultrasonic power (equal to $300 \mathrm{~W}$ in this case) was beneficial for the optimum $\mathrm{Ni}$ grain refinement of the resulting Ni-SiC NCs. Ni-SiC-300 NCs also demonstrated the highest microhardness (equal to $906.7 \mathrm{Hv}$ ), the best wear rate (equal to $17.8 \mathrm{mg} / \mathrm{min}$ ) and the best corrosion resistance judging by its lowest corrosion current density (equal to $0.032 \mu \mathrm{A} / \mathrm{mm}^{2}$ ).
\end{abstract}

Keywords: Ni-SiC NCs; Surface morphology; Property; Ultrasonic-assisted electrodeposition

\section{FULL TEXT}

(C) 2020 The Authors. Published by ESG (www.electrochemsci.org). This article is an open access article distributed under the terms and conditions of the Creative Commons Attribution license (http://creativecommons.org/licenses/by/4.0/). 